\title{
Respon Beberapa Varietas Padi (Oryza Sativa L.) terhadap Serangan Hama Penggerek Batang Padi dan Walang Sangit (Leptocorisa acuta Thubn.)
}

\author{
Response of Some Varieties of Rice (Oryza Sativa L.) to Pest Borer \\ and "Walang Sangit" (Leptocorisa acuta Thubn.) Attack
}

\author{
Wahyu Maulana $^{1}$, Suharto $^{1}$ dan Wagiyana ${ }^{1}$ \\ ${ }^{1}$ Program Studi Agroteknologi, Fakultas Pertanian, Universitas Jember \\ J1. Kalimantan 37, Kampus Tegal Boto, Jember 68121 \\ *E-mail: harto.unej@yahoo.com
}

Diterima 23 Februari 2017/Disetujui 23 Maret 2017

\begin{abstract}
Rice (Oryza sativa L.) is a major crops cultivated by farmers in Indonesia. However, rice production has decreased due to the pest attack. The decline in rice production due to the pests can be reduced by knowing the characteristics of pests and determining the effective ways to control it. One control can be done is by technical culture, wich is using resistant varieties. Plants have different responses to the attack of plant pests among the varieties with other varieties. Plants have a very high level response (highly resistant) and very low response (very vulnerable). Knowledge about the response of rice varieties against pests and their effect on the growth and production of rice is necessary so, using resistant varieties become more effective and efficient. This study was designed with a randomized block design (RBD) using 5 treatments varieties. Varieties tested were Cimelati, Logawa, Gorontalo, Inpari 13 and Inpari 31 and repeated 5 times. The results showed that the lowest rice bug population was in Gorontalo varieties amounted 9.20 per plot and the lowest rice stem borer population was in Inpari 31 amounted 0.86 per 10 observations clump. The lowest attak intensity of rice bug was in Gorontalo varieties amounted to $10.07 \%$ and the lowest attack intensity of rice stem borer was in Inpari 13 amounted to 5.23\%. The results also showed that Inpari had the highest production yield of 5.38 tonnes / ha compared with four other varieties.
\end{abstract}

Keywords: Rice Varieties, rice bug, rice stem borer.

\section{ABSTRAK}

Padi (Oryza sativa L.) merupakan tanaman pangan utama yang banyak dibudidayakan oleh petani di Indonesia. Namun, produksi padi mengalami penurunan akibat adanya serangan hama. Penurunan produksi padi akibat serangan hama dapat dikurangi dengan mengetahui karakteristik hama dan mengetahui cara yang efektif dalam mengendalikannya. Salah satu pengendalian yang dapat dilakukan adalah dengan melakukan pengendalian secara kultur teknis yaitu menggunakan varietas tahan. Tanaman memiliki respon yang berbeda terhadap serangan organisme pengganggu tumbuhan antara varietas satu dengan varietas lain. Respon tanaman mempunyai tingkat yang sangat tinggi (sangat tahan) dan sangat rendah (sangat rentan). Pengetahuan tentang respon varietas padi terhadap serangan hama serta pengaruhnya terhadap pertumbuhan dan produksi padi sangat diperlukan agar pengendalian hama dengan menggunakan varietas tahan menjadi lebih efektif dan efisien. Penelitian ini dirancang dengan Rancangan Acak Kelompok (RAK) menggunakan 5 perlakuan varietas. Varietas yang diuji adalah varietas Cimelati, Logawa, Gorontalo, Inpari 13 dan Inpari 31 dengan perlakuan diulang 5 kali. Hasil penelitian menunjukkan bahwa populasi hama walang sangit terendah yaitu pada varietas Gorontalo sebanyak 9.20 ekor per petak pengamatan dan populasi hama penggerek batang padi terendah pada varietas Inpari 31 yaitu 0,86 ekor per 10 rumpun pengamatan. Intensitas serangan hama walang sangit terendah pada varietas Gorontalo sebesar $10.07 \%$ dan intensitas serangan hama penggerek batang padi terendah pada varietas Inpari 13 sebesar 5.23\%. Hasil produksi juga menunjukkan bahwa varietas Inpari menunjukkan hasil produksi tertinggi yaitu 5.38 ton/ha dibandingkan empat varietas lainnya.

Kata Kunci: Varietas Padi, walang sangit, penggerek batang padi.

\section{PENDAHULUAN}

Padi (Oryza sativa L.) merupakan tanaman pangan utama yang banyak dibudidayakan oleh petani di Indonesia. Komoditas ini menjadi makanan pokok bagi sebagian besar penduduk Indonesia. Namun, produksi padi di Indonesia masih belum mencukupi kebutuhan konsumsi beras karena peningkatan kebutuhan beras tidak diimbangi dengan peningkatan atau perluasan areal pertanian, sehingga produksi padi cenderung mengalami penurunan. Menurut 
BPS Jawa Timur (2015), penurunan produksi padi di Pulau Jawa terjadi karena penurunan luas panen seluas 41.61 ribu hektar $(0.30 \%)$ dan penurunan produktivitas sebesar 0.17 $\mathrm{kw} / \mathrm{ha}(0.33 \%)$. Beberapa Kabupaten/Kota di Jawa Timur yang mengalami penurunan produksi padi terbesar kedua adalah Kabupaten Situbondo yaitu turun 9.51 ribu ton gabah kering giling $(-10.83 \%)$.

Faktor-faktor yang mempengaruhi rendahnya produktivitas padi salah satunya adalah adanya serangan hama tanaman padi. Penurunan produksi padi akibat serangan hama dapat dikurangi dengan mengetahui karakteristik hama dan mengetahui cara yang efektif dalam mengendalikannya. Salah satu pengendalian yang dapat dilakukan yaitu pengendalian secara kultur teknis dengan menanam varietas tahan. Tanaman memiliki respon yang berbeda terhadap serangan organisme pengganggu tumbuhan antara varietas satu dengan varietas lain. Respon tanaman mempunyai tingkat yang sangat tinggi (sangat tahan) dan sangat rendah (sangat rentan). Pengetahuan tentang respon varietas padi terhadap serangan hama serta pengaruhnya terhadap pertumbuhan dan produksi padi sangat diperlukan agar pengendalian hama dengan menggunakan varietas tahan menjadi lebih efektif dan efisien.

\section{BAHAN DAN METODE}

\section{Waktu dan tempat}

Penelitian ini dilaksanakan di Desa Bungatan, Kecamatan Bungatan, Kabupaten Situbondo pada bulan Januari sampai dengan bulan Mei 2016.

\section{Pelaksanaan Penelitian}

\subsection{Pembibitan Padi}

Benih direndam dengan menggunakan air selama 48 jam. Benih yang digunakan adalah benih yang tenggelam. Kemudian benih disemai pada lahan yang tersedia.

\subsection{Persiapan Lahan dan Penanaman}

Persiapan lahan dilakukan dengan pembajakan sawah terlebih dahulu, kemudian lahan dibagi menjadi 25 plot percobaan dengan ukuran masing-masing plot $2 \times 2 \mathrm{~m}^{2}$. Jarak tanam yang digunakan adalah $20 \times 20 \mathrm{~cm}$

\subsection{Pemeliharaan}

meliputi proses penyiangan, pengendalian penyakit, pemupukan dan pengairan. Pemupukan dilakukan sebanyak tiga kali yaitu pemupukan dasar (7 hari sebelum tanam), pupuk susulan 1 ( 7 hari setelah tanam) dan pupuk susulan 2 (40 hari setelah tanam) dengan menggunakan pupuk Urea, $\mathrm{KCl}$ dan SP-36.

\section{Parameter Pengamatan}

Pengamatan terhadap keberadaan hama diantanya yaitu populasi hama dan intensitas serangan hama, serta pengamatan terhadap pertumbuhan meliputi jumlah anakan, jumlah anakan produktif dan produksi. Intensitas serangan hama dapat dihitung dengan rumus:

$$
I=\frac{a}{b} x 100
$$

Keterangan:

I $\quad$ : Intensitas kerusakan tanaman

a : Jumlah tanaman atau bagian tanaman yang menunjukkan gejala serangan

b : jumlah keseluruhan tanaman atau unit sampel yang diamati

Nilai skala untuk kategori serangan hama walang sangit yaitu normal $=0$, ringan $=1-25 \%$, sedang $=26$ $50 \%$, berat $=51-75 \%$, sangat berat $=76-100 \%$ (Leatemia dan Rumthe, 2011). Tingkat ketahanan terhadap serangan hama penggerek (sundep), yaitu sangat tahan $=0$, tahan $=$ $0-20 \%$, agak tahan $=21-40 \%$, agak peka $=41-60 \%$, peka $=$ $61-80 \%$ dan sangat peka $=81-100 \%$, sedangkan tingkat ketahanan terhadap serangan hama penggerek pada tahap generatif (beluk), yaitu sangat tahan $=0$, tahan $=0-10 \%$, agak tahan $=11-25 \%$, agak peka $=26-40 \%$, peka $=41-$ $60 \%$ dan sangat peka $=61-100 \%$ (Dewi dkk., 2002).

Menurut Sijabat (2007), penghitungan hasil produksi masing-masing plot (kg/plot) dikonversikan kedalam satuan ton/ha dengan menggunakan persamaan:

$$
Y=\frac{10.000 m^{2}}{L\left(m^{2}\right)} X \frac{X(K g)}{1000 K g}
$$

Keterangan:

$\begin{array}{ll}\mathrm{Y} & \text { : Produksi (ton/ha) } \\ \mathrm{X} & \text { : Produksi dalam satu plot }(\mathrm{kg}) \\ \mathrm{L} & : \text { Luas Plot }\left(\mathrm{m}^{2}\right)\end{array}$

\section{Analissa Data}

Data populasi, intensitas serangan serta pertumbuhan dan produksi padi dirancang dengan Rancangan Acak Kelompok (RAK) menggunakan 5 perlakuan varietas. Varietas yang diuji adalah: (a) padi varietas Gorontalo; (b) padi varietas Inpari 13; (c) padi varietas Inpari 31; (d) Padi varietas Cimelati; dan (e) padi varietas Logawa dengan perlakuan diulang 5 kali. Apabila terdapat beda nyata maka dilanjutkan dengan uji Scott-Knott 5\%.

\section{HASIL DAN PEMBAHASAN}

\section{Populasi Hama Walang Sangit dan Penggerek Batang Padi}

Hasil pengamatan populasi walang sangit pada semua varietas menunjukkan bahwa pada pengamatan $70 \mathrm{hst}$ populasi walang sangit meningkat, kemudian pada pengamatan 77-84 hst populasi walang sangit menurun, kecuali pada varietas Cimelati yang mengalami peningkatan pada saat pengamatan 84 hst yaitu dari 15,60 ekor 
meningkat menjadi 16,00 ekor. Populasi walang sangit terendah pada pengamatan 84 hst yaitu varietas Gorontalo sebesar 9,20 ekor dan berbeda nyata dengan varietas
Cimelati, Logawa dan Inpari 31, tetapi tidak berbeda nyata dengan

Tabel 1 Rata-Rata Populasi Hama Walang Sangit

Populasi Hama (ekor/4 $\mathrm{m}^{2}$ ) pada Varietas

Umur Tanaman (hst)

\begin{tabular}{cccccc}
\cline { 2 - 5 } Umur Tanaman (hst) & Cimelati & Logawa & Gorontalo & Inpari 13 & Inpari 31 \\
\hline 63 & $17.40 \mathrm{~b}$ & $15.60 \mathrm{~b}$ & $12.60 \mathrm{a}$ & $16.20 \mathrm{~b}$ & $17.00 \mathrm{~b}$ \\
70 & $18.40 \mathrm{~b}$ & $16.80 \mathrm{~b}$ & $13.60 \mathrm{a}$ & $16.40 \mathrm{~b}$ & $17.20 \mathrm{~b}$ \\
77 & $15.60 \mathrm{a}$ & $14.20 \mathrm{a}$ & $12.80 \mathrm{a}$ & $15.40 \mathrm{a}$ & $14.40 \mathrm{a}$ \\
84 & $16.00 \mathrm{c}$ & $13.20 \mathrm{~b}$ & $9.20 \mathrm{a}$ & $11.00 \mathrm{a}$ & $13.80 \mathrm{~b}$
\end{tabular}

Keterangan: Angka-angka yang diikuti huruf yang sama pada baris yang sama menunjukkan tidak berbeda nyata berdasarkan Uji Scott-Knott $5 \%$.

Tabel 2 Rata-Rata Populasi Hama Penggerek Batang Padi pada Pengamatan Tanaman Umur 63 hst sampai dengan 84 hst.

\begin{tabular}{|c|c|c|c|c|c|}
\hline \multirow{2}{*}{ Umur Tanaman (hst) } & \multicolumn{5}{|c|}{ Populasi Hama (ekor/10 rumpun) pada Varietas } \\
\hline & Cimelati & Logawa & Gorontalo & Inpari 13 & Inpari 31 \\
\hline 63 & $4.04 b$ & $3.44 \mathrm{a}$ & $8.16 \mathrm{c}$ & $3.32 \mathrm{a}$ & $3.40 \mathrm{a}$ \\
\hline 70 & $2.90 \mathrm{~b}$ & $2.06 \mathrm{a}$ & $6.24 c$ & $2.22 \mathrm{a}$ & $2.20 \mathrm{a}$ \\
\hline 77 & $2.14 \mathrm{a}$ & $1.88 \mathrm{a}$ & $4.30 \mathrm{~b}$ & $1.88 \mathrm{a}$ & $2.08 \mathrm{a}$ \\
\hline 84 & $1.00 \mathrm{a}$ & $0.96 \mathrm{a}$ & $1.98 \mathrm{~b}$ & $0.96 \mathrm{a}$ & $0.86 a$ \\
\hline
\end{tabular}

Keterangan: Angka-angka yang diikuti huruf yang sama pada baris yang sama menunjukkan tidak berbeda nyata berdasarkan Uji Scott-Knott 5\%.

Tabel 3. Rata-Rata Intensitas Serangan Hama Walang Sangit dan Penggerek Batang Padi

\begin{tabular}{lcrrrrr}
\hline \multirow{2}{*}{ Jenis Hama } & Umur Tanaman & \multicolumn{5}{c}{ Intensitas Serangan Hama (\%) pada Varietas } \\
\cline { 3 - 7 }$(\mathrm{hst})$ & 63 & Cimelati & Logawa & Gorontalo & Inpari 13 & Inpari 31 \\
\hline \multirow{3}{*}{ Walang } & 70 & $11.72 \mathrm{~b}$ & $10.36 \mathrm{a}$ & $10.70 \mathrm{a}$ & $10.10 \mathrm{a}$ & $11.20 \mathrm{~b}$ \\
Sangit & 77 & $13.62 \mathrm{~b}$ & $11.12 \mathrm{a}$ & $10.79 \mathrm{a}$ & $11.15 \mathrm{a}$ & $13.11 \mathrm{~b}$ \\
& 84 & $14.79 \mathrm{~d}$ & $13.08 \mathrm{c}$ & $9.57 \mathrm{a}$ & $10.59 \mathrm{~b}$ & $14.93 \mathrm{~d}$ \\
\hline \multirow{3}{*}{ penggerek } & 63 & $16.39 \mathrm{~d}$ & $14.87 \mathrm{c}$ & $9.21 \mathrm{a}$ & $11.61 \mathrm{~b}$ & $15.50 \mathrm{c}$ \\
batang padi & 70 & $8.41 \mathrm{~b}$ & $6.84 \mathrm{a}$ & $19.35 \mathrm{c}$ & $6.96 \mathrm{a}$ & $7.15 \mathrm{a}$ \\
& 77 & $6.85 \mathrm{~b}$ & $5.66 \mathrm{a}$ & $17.15 \mathrm{c}$ & $5.46 \mathrm{a}$ & $6.01 \mathrm{a}$ \\
\hline
\end{tabular}

Keterangan : Angka-angka yang diikuti huruf yang sama pada baris yang sama menunjukkan tidak berbeda nyata berdasarkan Uji Scott-Knott $5 \%$.

Hasil pengamatan populasi penggerek batang padi (tabel 2), menunjukkan bahwa pada semua varietas mengalami penurunan populasi penggerek batang padi mulai dari 63-84 hst. Populasi penggerek batang padi terbanyak 
mulai dari 63-84 hst adalah pada varietas Gorontalo dengan rata-rata populasi sebanyak 8,16 ekor dan berbeda nyata dengan empat varietas lainnya yang terjadi sampai dengan akhir pengamatan.

Tabel 4. Rata-Rata Intensitas Serangan dan Kategori Serangan Hama Walang Sangit

\begin{tabular}{lcc}
\hline Varietas & Intensitas serangan $(\%)$ & Kategori serangan \\
\hline Cimelati & 14.13 & Ringan \\
Logawa & 12.36 & Ringan \\
Gorontalo & 10.07 & Ringan \\
Inpari 13 & 10.86 & Ringan \\
Inpari 31 & 13.68 & Ringan \\
\hline
\end{tabular}

Keterangan: $\quad$ Normal $=0$, Ringan $=1-25 \%$, Sedang $=26-50 \%$, Berat $=51-75 \%$, Sangat Berat $=76-100 \%($ Leatemia dan Rumthe, 2011).

Tabel 5. Rata-Rata Intensitas Serangan Penggerek Batang Padi dan Nilai Ketahanan

\begin{tabular}{lcc}
\hline Varietas & Rata-rata intensitas serangan $(\%)$ & Tipe Ketahanan \\
\hline Cimelati & 6.52 & Tahan \\
Logawa & 5.56 & Tahan \\
Gorontalo & 16.09 & Agak Tahan \\
Inpari 13 & 5.23 & Tahan \\
Inpari 31 & 5.49 & Tahan \\
\hline
\end{tabular}

Keterangan : Sangat Tahan $=0$, Tahan $=0-10 \%$, Agak Tahan $=11-25 \%$, Agak Peka = 26-40\%, Peka = 41-60\% Dan Sangat Peka $=61-100 \%$ (Dewi dkk., 2002).

\section{Intensitas Serangan Hama Walang Sangit dan Penggerek Batang Padi}

Berdasarkan data (tabel 3), hasil pengamatan intensitas serangan hama walang sangit menunjukkan bahwa varietas Cimelati, Logawa dan Inpari 31 dari pengamatan 63-84 hst meningkat, berbeda dengan varietas Gorontalo yang mengalami penurunan intensitas serangan pada pengamatan 77-84 hst dan juga pada varietas Inpari 13 mengalami penurunan intensitas serangan pada pengamatan 77 hst, tetapi meningkat lagi pada akhir pengamatan.

Data (Tabel 2) juga menunjukkan bahwa intensitas serangan penggerek batang padi tertinggi dari pengamatan 63-84 hst adalah varietas Gorontalo. Intensitas serangan penggerek batang padi pada varietas gorontalo sebesar $12,45 \%$ (63 hst) dan berbeda nyata dengan empat varietas lainnya. Hingga pengamatan terakhir varietas Intensitas serangan penggerek batang padi dari pengamatan 63-84 hst menurun pada semua varietas padi.

Varietas Gorontalo merupakan varietas yang paling rendah terkena serangan hama walang sangit dengan ratarata intensitas serangan sebesar $9,21 \%$ dan berbeda nyata dengan empat varietas lainnya. Intensitas serangan walang sangit pada semua varietas termasuk dalam kategori serangan ringan (Tabel 4).

Rata-rata intensitas serangan penggerek batang padi pada varietas Gorontalo menunjukkan hasil tertinggi yaitu $16,09 \%$ dan termasuk dalam kategori agak tahan, sedangkan empat varietas lainnya yaitu Cimelati, Logawa, Inpari 13 dan Inpari 31 dengan intensitas serangan masing-masing $6,52 \%, 5,56 \%, 5,23 \%$ dan 5,49\% masuk dalam kategori tahan (Tabel 5).
Hasil penelitian populasi hama walang sangit menunjukkan bahwa populasi tertinggi yaitu pada saat padi berumur 70 hst. Tingginya populasi walang sangit dikarenakan pada saat itu tanaman padi memasuki stadia masak susu. Menurut Sidim (2009), populasi walang sangit cukup tinggi karena makanan yang cukup tersedia untuk perkembangannya karena pada umumnya walang sangit menyerang tanaman padi pada saat fase masak susu. Ratarata populasi walang sangit pada varietas Gorontalo hingga pengamatan terakhir merupakan populasi terendah diantara varietas lainnya, hal ini disebabkan karena jumlah anakan pada varietas gorontalo lebih sedikit pada akhir pengamatan sehingga imago walang sangit lebih menyukai inang yang lebih banyak menghasilkan bulir untuk memenuhi kebutuhan makanannya. Menurunnya populasi walang sangit dikarenakan tanaman yang menjadi bahan makanannya tidak sesuai lagi karena bulir padi mulai mengeras. Tanaman padi yang menjadi makanannya tidak sesuai, maka akan berpengaruh buruk terhadap kehidupan serangga (Rismunandar, 1993).

Walang sangit menyerang pada saat tanaman memasuki fase reproduksi. Serangan yang terjadi sebelum masak susu menyebabkan gabah hampa, sedangkan pada saat bulir yang telah berisi menyebabkan gabah berwarna buram sehingga kualitasnya rendah (Rosba dan Catri, 2015). Data hasil pengamatan menunjukkan bahwa pada semua varietas intensitas serangan walang sangit termasuk kedalam kategori ringan. Serangan terendah yaitu pada varietas Gorontalo sebesar $10.07 \%$ (Tabel 4).

Perilaku penggerek batang padi berbeda dalam setiap varietas dan biasanya banyak ditemukan pada inang yang disenangi. Selain itu, tingkat keseimbangan populasi penggerek batang padi di suatu daerah dapat berubah bila 
terjadi perubahan varietas (Ngatimin, 2005). Populasi penggerek batang padi mulai dari pengamatan 63-84 hst terus menurun, hal ini diduga karena pada fase reproduksi tanaman padi mengalami perubahan sifat fisiologis. Menurut Anwar dan Budiyanto (2013), populasi penggerek batang padi pada fase reproduksi semakin turun karena pada fase tersebut tanaman padi kekurangan cairan khususnya pada batang dan mengerasnya batang padi yang menyebabkan hama penggerek batang padi kurang menyukainya.

Respon varietas terhadap tingkat serangan hama penggerek batang padi berbeda-beda. Rata-rata intensitas serangan penggerek batang padi tertinggi pada varietas Gorontalo. Hal ini diduga karena adanya perbedaan karekteristik setiap varietas, misalnya varietas Gorontalo mempunyai jumlah anakan yang lebih sedikit sehingga agak rentan terhadap serangan hama penggerek batang padi, sedangkan varietas cimelati, logawa, serta Inpari 13 dan 31 mempunyai anakan yang lebih produktif daripada varietas Gorontalo. Menurut Matsuo dalam Soejitno (1984), varietas yang mempunyai potensi anakan tinggi cenderung kurang rentan terhadap serangan penggerek karena kemampuannya membentuk tunas baru. Selain itu, ukuran diameter batang pada varietas Gorontalo lebih besar dari pada empat varietas lainnya. Menurut hasil penelitian Soejitno dkk (1995), menunjukkan bahwa sifat ketahanan penggerek batang padi lebih bersifat fisik, karena ukuran batang yang kecil tidak disukai oleh hama penggerek batang padi.

Tinggi rendahnya populasi penggerek batang padi juga berpengaruh terhadap intensitas serangan penggerek batang padi. Data hasil pengamatan menunjukkan bahwa populasi penggerek batang padi terus menurun dari 63-84 hst (Tabel 2) dan hal tersebut sama dengan data intensitas serangan penggerek batang padi yaitu juga mengalami penurunan dari pengamatan 63-84 hst (Tabel 3). Semakin tinggi kelimpahan maka semakin tinggi pula persentase serangan, sebaliknya semakin rendah kelimpahan penggerek batang padi maka semakin rendah pula persentase serangannya di lapangan (Aryantini dkk., 2015).
Respon ketahanan yang diberikan oleh varietas Gorontalo terhadap intensitas serangan hama penggerek batang padi tergolong rendah. Varietas Gorontalo merupakan varietas dengan kategori ketahanan agak tahan, sedangkan empat varietas lainnya memberikan respon yang lebih tinggi yaitu termasuk dalam kategori tahan (Tabel 5). Semua tanaman yang di uji terserang oleh penggerek batang padi, tetapi pada varietas Cimelati, Logawa, Inpari 13 dan Inpari 31 memiliki ketahanan yang lebih kuat daripada varietas Gorontalo karena intensitas serangannya rendah dan populasi yang menyerang lebih sedikit. Varietas Cimelati, Logawa, Inpari 13 dan Inpari 31 juga memiliki jumlah anakan lebih banyak daripada varietas Gorontalo. Selain itu, faktor lain yang mempengaruhi tanaman yang diuji yaitu mempunyai zat kimia tertentu sehingga mempengaruhi pertumbuhan larva penggerek. Tetapi, kandungan kimia pada tanaman uji belum diketahui. Kerentanan varietas padi terhadap serangan penggerek batang padi disebabkan oleh beberapa faktor, tetapi faktor kimia berpengaruh lebih kuat (Manwan, 1975). Kemungkinan faktor kimia dapat menghambat pertumbuhan larva, atau karena tidak adanya senyawa kimia tertentu justru yang dibutuhkan oleh penggerek batang padi. Larva penggerek yang hidup pada media yang mengandung senyawa benzoate dan asam salisilat dari ekstrak batang padi mampu menghambat pertumbuhan larva penggerek (Munakata dan Okamoto, 1967).

\section{Pertumbuhan dan produksi}

Hasil pengamatan jumlah anakan tiap varietas menunjukkan bahwa varietas Gorontalo merupakan varietas yang mempunyai jumlah anakan paling sedikit yaitu 10.54 anakan dan berbeda nyata dengan empat varietas lainnya (Tabel 6). Data (Tabel 6) juga menunjukkan bahwa jumlah anakan produktif paling rendah adalah varietas Gorontalo sebesar 6.80 anakan dan berbeda nyata dengan empat varietas lainnya.

Tabel 6 Pertumbuhan dan Produksi pada Lima Varietas Padi

Parameter Pertumbuhan

\begin{tabular}{|c|c|c|c|c|}
\hline Varietas & $\sum$ Anakan (56 hst) & $\sum$ Anakan produktif (84 hst) & $\begin{array}{l}\text { Rata-rata jumlah } \\
\text { bulir }\end{array}$ & Produksi (ton/ha) \\
\hline Cimelati & $20.30 \mathrm{a}$ & $15.60 \mathrm{a}$ & $139.84 b$ & $3.87 \mathrm{a}$ \\
\hline Logawa & $20.62 \mathrm{a}$ & $16.34 \mathrm{a}$ & $138.85 b$ & $4.56 \mathrm{~b}$ \\
\hline Gorontalo & $10.54 \mathrm{c}$ & $6.80 \mathrm{~b}$ & $357.45 a$ & $3.41 \mathrm{a}$ \\
\hline Inpari 13 & $20.90 \mathrm{a}$ & $16.24 \mathrm{a}$ & $116.78 \mathrm{c}$ & $5.38 \mathrm{~b}$ \\
\hline Inpari 31 & $19.70 \mathrm{~b}$ & $16.08 \mathrm{a}$ & $121.11 \mathrm{c}$ & $4.31 \mathrm{~b}$ \\
\hline
\end{tabular}

Keterangan: Angka-angka yang diikuti huruf yang sama pada kolom yang sama menunjukkan tidak berbeda nyata berdasarkan Uji Scott-Knott 5\%. 
Data (Tabel 6) hasil pengamatan produksi tiap varietas padi menunjukkan bahwa varietas Inpari 13 merupakan varietas yang mempunyai produksi paling tinggi diantara varietas lainnya yaitu sebesar 5.38 ton/ha dan berbeda nyata dengan varietas Cimelati dan Gorontalo masing-masing sebesar 3.87 ton/ha dan 3.41 ton/ha, tetapi tidak berbeda nyata dengan varietas Logawa dan Inpari 31 masing-masing sebesar 4.56 ton/ha dan 4.31 ton/ha.

Menurut Kuswanto (1997), untuk menunjang produksi dan produktivitas, diperlukan penggunaan varietas unggul dan bermutu. Data hasil pengamatan menunjukkan bahwa produksi hasil tertinggi yaitu pada varietas Inpari 13 sebesar 5,38 ton/ha sedangkan paling rendah pada varietas Gorontalo 3,41 ton/ha (Tabel 6), tetapi produksi yang dihasilkan tergolong sangat rendah. Rata-rata produksi yang dapat dihasilkan pada varietas Inpari 13 sebesar 6,59 ton/ha, Gorontalo dengan potensi hasil sebesar 19 ton/ha, varietas Cimelati, Logawa dan Inpari 31 rata-rata produksi yang dihasilkan masing-masing sebesar 6 ton/ha, 6,8 ton/ha dan 6 ton/ha (Suprihatno dkk., 2010).

Rendahnya hasil produksi ini disebabkan oleh adanya serangan hama. Menurut Suharto dan Usyati (2009), kerugian hasil yang disebabkan oleh setiap persen gejala beluk berkisar 1-3\% dengan rata-rata 1,2\%. Damayanti dkk (2015), juga menyatakan bahwa kehilangan hasil akibat serangan hama penggerek batang padi dapat mencapai 10$30 \%$ dan serangan berat dapat menyebabkan puso. Sedangkan kehilangan hasil yang disebabkan oleh adanya serangan hama walang sangit dapat menurunkan hasil tanaman padi rata-rata $40 \%$ dan serangan berat dapat mencapai 100\% (Nizar, 2011).

\section{KESIMPULAN}

Respon varietas terhadap populasi hama walang sangit dan penggerek batang padi berbeda antar varietas. Varietas Inpari 31 menunjukkan rata-rata populasi terendah terhadap hama penggerek batang padi yaitu 0.86 ekor per 10 rumpun pengamatan. Selain itu, varietas Gorontalo menunjukkan rata-rata populasi terendah terhadap hama walang sangit yaitu 9.20 ekor per petak pengamatan. Respon varietas terhadap intensitas serangan hama walang sangit dan penggerek batang padi berbeda antar varietas. Varietas Inpari 13 menunjukkan rata-rata intensitas serangan terendah terhadap serangan hama pengerek batang padi yaitu $5.23 \%$. Selain itu, varietas Gorontalo menunjukkan rata-rata intensitas serangan terendah terhadap hama walang sangit yaitu $10.07 \%$. Perbedaan varietas berpengaruh terhadap pertumbuhan dan hasil produksi padi. Varietas Inpari 13 menunjukkan hasil produksi paling tinggi yaitu 5.38 ton/ha dan produksi terendah pada varietas Gorontalo yaitu 3.41 ton/ha.

\section{DAFTAR PUSTAKA}

Anwar, H., dan S. Budiyanto. 2013. Identifikasi Populasi Hama Penggerek Batang Padi di Lokasi SL-PTT di
Kabupaten Banjarnegara. Seminar Nasional. Balai Pengkajian teknologi Pertanian (BPTP) Jawa Tengah. Aryantini, L., I. W. Supartha, I. N. Wijaya. 2015. Kelimpahan Populasi dan Serangan Penggerek Batang Padi pada Tanaman Padi di Kabupaten Tabanan. Agroteknologi Tropika, 4(3): 203-212.

BPS Jawa Timur. 2015. Produksi Padi dan Palawija. Berita Resmi Statistik. Jawa Timur.

Damayanti, E., G. Mudjiono dan S. Karindah. 2015. Perkembangan Populasi Larva Penggerek Batang dan Musuh Alaminya pada Tanaman Padi (Oryza sativa L.) PHT. HPT, 3(2): 18-24.

Dewi, I. S., A. Apriana, A. Sisharmini dan I. H. Somantri. 2002. Evaluasi Ketahanan Tanaman Padi Haploid Ganda Calon Tetua Padi Hibrida terhadap Wereng Batang Coklat dan Hawar Daun Bakteri. Bul. Agron., 35(1): 15-21.

Kuswanto, H. 1997. Analisis Benih. Yogyakarta: Andi.

Leatemia, J. A., dan R. Y. Rumthe. 2011. Studi Kerusakan Akibat Serangan Hama pada Tanaman Pangan di Kecamatan Bula, Kabupaten Seram Bagian Timur, Propinsi Maluku. Agroforestri, 6(1): 52-56.

Manwan, I. 1975. Resistance of Rice Varieties to Yellow Borer, Triporyza incertulas (Walker). [Tesis]. Philippines: UPLB

Munakata, K. and D. Okamoto. 1967. The Major Insect Pests of the Rice Plant. Baltimore: Johns Hopkins Press.

Ngatimin, S. N. A. 2005. Pengaruh Pola Tanam Campuran Beberapa Varietas Padi Terhadap Populasi dan Intensitas Serangan Beberapa Hama Tanaman Padi. Sains \& Teknologi, 5(2): 85-89.

Nizar, M. 2011. Pengaruh Beberapa Jenis Bahan Organik Terhadap Pertumbuhan dan Hasil Tanaman Padi (Oryza sativa L.) Metode Sri (The System of Rice Intensification). Skripsi. Universitas Andalas, Padang.

Rismunandar. 1993. Hama Tanaman Pangan dan Pembasminya. Bandung: Sinar Baru Alegesindo.

Rosba, E., dan M. Catri. 2015. Pengaruh Ekstrak Biji Bengkuang terhadap Walang Sangit (Leptocorisa acuta Thunb.) pada Tanaman Padi. Penelitian Pendidikan IPA, 1(2): 76-82.

Sidim, F. 2009. Penyebaran Hama Walang Sangit Leptocorisa oratorius F. (Hemiptera; Alydidae) pada Tanaman Padi di Kabupaten Minahasa. Skripsi. Fakultas Pertanian Universitas Sam Ratulangi Manado.

Sijabat, O. N. S. B. R. 2007. Epidemi Penyakit Blas (Pyricularia oryzae Cav.) pada Beberapa Varietas Padi Sawah (Oryza sativa L) dengan Jarak Tanam Berbeda di Lapangan. Skripsi. Universitas Sumatera Utara. Medan.

Soejitno, J. 1984. Hubungan Inokulasi Larva Penggerek Padi Kuning (Tryporyza incertulas Walker) (Lepidoptera: Pyralidae) dengan Tunas Terserang dan Kehilangan 
Hasil Padi. Tidak Diterbitkan. Disertasi. Bogor: Program Pascasarjana, Institut Pertanian Bogor.

Soejitno, J., I. Hanarida, dan Bahagiawati. 1995. Evaluation of several wild rice to rice stemborer (Scirpophaga innotata). Makalah Balittan Bogor No. 38.

Suprihatno, B., Aan, A. D. Satoto., Baehaki, S.E.,
Suharto, H. dan Usyati. 2009. Pengendalian Hama Penggerek Batang Padi. Balai Besar Penelitian Tanaman Padi. Departemen Pertanian.

Suprihanto., Agus, S., Dewi, I., Putu, W., dan Hasil, S. 2010. Deskripsi Varietas Padi. Balai Besar Penelitian Tanaman Padi.. 